\title{
Effect of Time (Season, Surgical Starting Time, Waiting Time) on Patients with Gastric Cancer
}

This article was published in the following Dove Press journal:

Risk Management and Healthcare Policy

\section{Dong Peng $\mathbb{D}^{*}$ \\ Ying-Ying Zou* \\ Yu-Xi Cheng \\ Wei Tao iD \\ Wei Zhang}

Department of Gastrointestinal Surgery, The First Affiliated Hospital of Chongqing Medical University, Chongqing, 400016,

People's Republic of China

*These authors contributed equally to this work
Correspondence: Wei Zhang

Department of Gastrointestinal Surgery,

The First Affiliated Hospital of Chongqing

Medical University, Chongqing, 400016,

People's Republic of China

Tel +86-I3808353353

Email cyzhangwei@hotmail.com
Purpose: The purpose of the present study was to evaluate the effect of time (season, surgical starting time in the daytime, preoperative waiting time) on patients with gastric cancer.

Methods: A retrospective collection of medical records of patients who underwent gastrectomy at a single clinical center from January 2013 to December 2018 was performed. Medical records were collected, and short-term outcomes and long-term survival were analyzed by different time groups.

Results: A total of 586 patients were included in this study. In terms of surgical starting time, the midday group had a shorter operation time $(\mathrm{p}=0.017)$ but more complications $(p=0.048)$ than the non-midday group. No significant difference was found based on the season of gastrectomy. The long preoperative waiting group had a shorter postoperative hospital stay than the short waiting group $(p=0.026)$. No significant difference was found between the short-waiting group and long-waiting group in overall survival for all clinical stages. Age $(\mathrm{p}=0.040, \mathrm{HR}=1.017,95 \% \mathrm{CI}=1.001-1.033), \mathrm{BMI}(\mathrm{p}<0.001, \mathrm{HR}=0.879,95 \%$ $\mathrm{CI}=0.844-0.953)$ and clinical stage $(\mathrm{p}<0.001, \mathrm{HR}=2.053,95 \% \mathrm{CI}=1.619-2.603)$ were independent prognostic factors predicting overall survival; however, season of gastrectomy, surgical starting time and preoperative waiting time were not identified as independent prognostic factors.

Conclusion: Surgical starting time at the midday could cause more complications, and surgeons should be careful when the surgical starting time is midday.

Keywords: gastric cancer, season, waiting time, surgical starting time

\section{Introduction}

Gastric cancer is generally acknowledged as one of the most common malignant tumors in the world, with approximately 1 million new cases diagnosed every year. ${ }^{1,2}$ Radical gastrectomy is still a recommended method for curable gastric cancer. ${ }^{3}$ There are a multiple number of factors that can affect short-term and long-term outcomes, including BMI, age, pathological tumor stage, and histologically differentiated types. ${ }^{4-6}$

The workload of surgeons and anesthesiologists can increase the adverse events of surgeries. ${ }^{7}$ Patients who are anesthetized at different times of the day may experience different clinical outcomes. ${ }^{8}$ Long working hours of work can cause loss of concentration, lack of sleep and fatigue. ${ }^{7,9}$ There is a clear correlation between the start time of surgery and adverse events, with the highest adverse events in the afternoon. ${ }^{8}$ Prior studies reported that the surgery starting time affected the prognosis of patients in general surgery, heart surgery, gynecologic surgery, orthopedic surgery and neurosurgery. ${ }^{10-12}$ 
The preoperative waiting time before surgery might also affect the short-term and long-term outcomes. However, as previously described, a waiting time beyond more than 90 days before surgery would not affect overall survival in patients with clinical stages I, II and IIII. ${ }^{13-15}$ Previous studies have proven that the birth season may affect the incidence of tumors, and furthermore, tumors diagnosed in winter may affect the prognosis as well. ${ }^{16,17}$ However, one study reported that the diagnosis season did not affect the prognosis of gastric cancer. ${ }^{18}$

The effect of preoperative waiting time, surgical staring time in the daytime and season of gastrectomy remain unclear because of limited research. Therefore, the purpose of the present study was to explore the effect of time (season, surgical starting time, preoperative waiting time) on patients with gastric cancer.

\section{Patients and Methods}

\section{Patients}

A retrospective collection of medical records of patients who underwent gastrectomy at a single clinical center from January 2013 to December 2018 was performed. This study was approved by the ethics committee (2020-649), and all patients signed informed consent forms. The inclusion criteria were as follows: 1. Patients were diagnosed with gastric cancer by pathology biopsy; and 2. Patients underwent gastrectomy for clinical stage I/II/III disease. The exclusion criteria were as follows: 1. Incomplete medical records; 2 . Neoadjuvant chemotherapy before gastrectomy; 3. Combination with other cancers; and 4. Gastrectomy started at night or evening. A total of 751 patients met the inclusion criteria of 803 patients in the database. Of these, 165 patients were excluded. Finally, a total of 586 patients were included in the study (Figure 1).

\section{Definition}

The season of gastrectomy was defined according to the location of the clinical center: spring was from March to May, summer was from June to August, autumn was from September to November and winter was from December to February. The preoperative waiting time was defined as the time from pathological diagnosis of gastric cancer to gastrectomy. The surgical starting time was divided into two groups: the midday group (12 to 14 o'clock) and the non-midday group (8 to 12, 14-18 o'clock). Complications were evaluated by Clavien-Dindo classification, and the grades $\mathrm{I}-\mathrm{V}$ were included in this study. ${ }^{19}$ TNM stage was based on the UICC tumor lymph node metastasis classification system definition. Overall survival was defined as the time from gastrectomy to death or the end of the study if the patient was still alive.

\section{Data Collection}

The baseline information was retrospectively collected, including sex, age, BMI, season of gastrectomy, comorbidity, preoperative waiting time, surgical starting time and

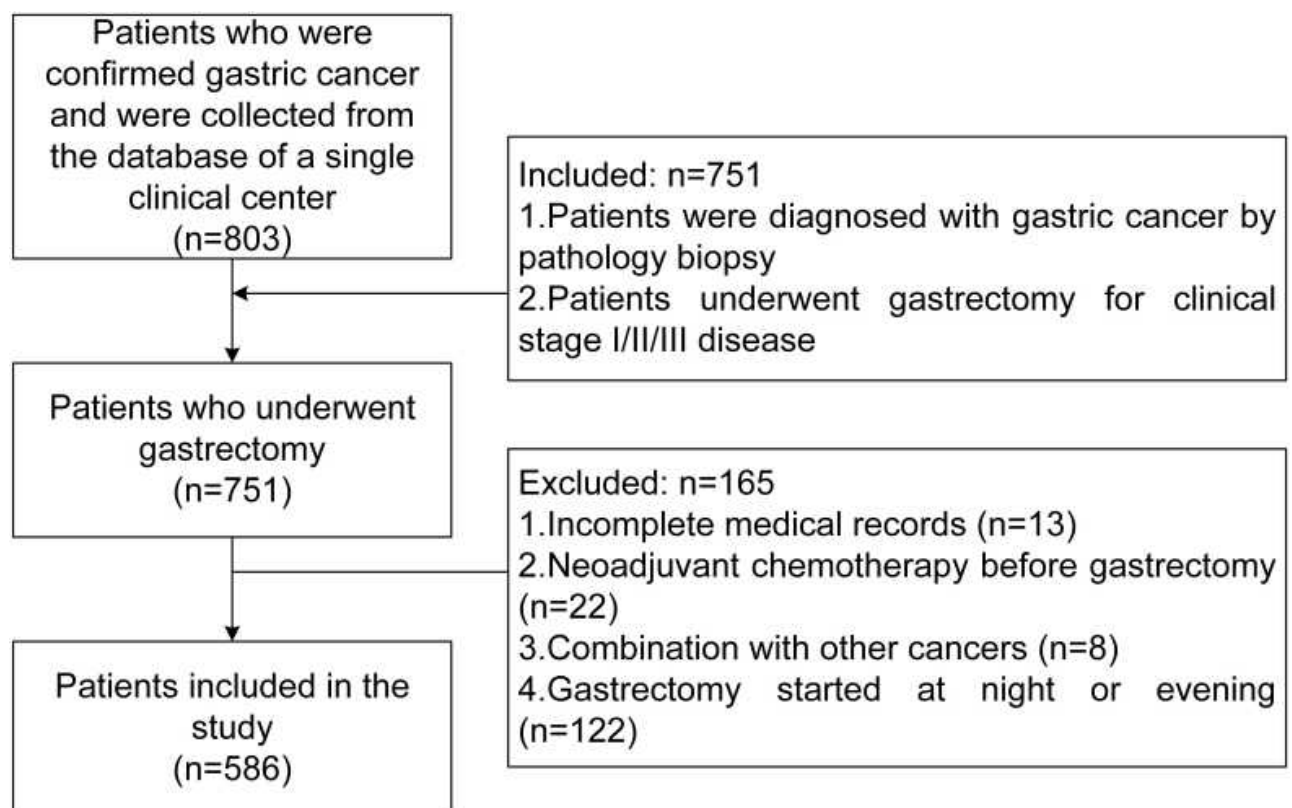

Figure I Inclusion and exclusion criteria of patients with gastric cancer. 
preoperative clinical stage. The operation information included surgical procedure, reconstruction method, operation time, estimated blood loss and number of retrieved lymph nodes. The postoperative information included postoperative hospital stay, pathological stage and overall survival time.

\section{Statistical Analysis}

The median and range or the mean and standard deviation were used for continuous variables. The preoperative waiting time was divided into a long-waiting group and a short-waiting group according to the median. The surgical starting time was divided into a midday group and a non-midday group. The Mann-Whitney- $U$ test and chi-square test were used to compare the differences between the two groups. The season of gastrectomy was divided into four groups: spring, summer, autumn and winter. The Kruskal-Wallis test and chi-square test were used to compare the differences across the four groups. The Log-rank test and Cox-proportional hazards model were used to analyze overall survival. Data were analyzed using SPSS (version 20.0) statistical software. A bilateral $\mathrm{p}$ value of $<0.05$ was considered statistically significant.

\section{Results}

\section{Clinical Characteristics of the Patients}

A total of 586 patients were included in this study, and all the patients underwent gastrectomy by two experienced surgeons on the same team in this study. Sex, age, BMI, season of gastrectomy, comorbidity, preoperative waiting time, surgical starting time, preoperative clinical stage, surgical procedure, reconstruction method, operation time, estimated blood loss, number of retrieved lymph nodes, postoperative hospital stay, complications and the pathological stage are shown in Table 1.

\section{Outcomes Associated with the Surgical Starting Time}

The surgical starting time was divided into a midday group and a non-midday group according to the median. The operation time, estimated blood loss, number of retrieved lymph nodes, complications and postoperative hospital stay were compared between the two groups. The midday group had a shorter operation time $(\mathrm{p}=0.017)$ but more complications $(\mathrm{p}=0.048)$ (Table 2$)$.
Table I Clinical Characteristics of the Patients

\begin{tabular}{|c|c|}
\hline Characteristics & No. 586 \\
\hline \multicolumn{2}{|l|}{ Sex } \\
\hline Male/Female & 418 (71.3\%)/168 (28.7\%) \\
\hline Age, year (mean, SD) & $60.7( \pm 10.7)$ \\
\hline BMI, kg/m² (mean, SD) & $23.2( \pm 27.9)$ \\
\hline \multicolumn{2}{|l|}{ Season of gastrectomy } \\
\hline Spring/Summer/Autumn/Winter & $\begin{array}{c}158(27.0 \%) / 157(26.8 \%) / 150 \\
(25.6 \%) / 121 \quad(20.6 \%)\end{array}$ \\
\hline Comorbidity & $216(36.9 \%)$ \\
\hline $\begin{array}{l}\text { Preoperative waiting time, day } \\
\text { (median, range) }\end{array}$ & $10(1-97)$ \\
\hline $\begin{array}{l}\text { Surgical starting time } \\
\text { Midday/Non-midday }\end{array}$ & I 32 (22.5\%)/454 (77.5\%) \\
\hline Clinical stage $1 / I / / I I I$ & $148(25.3 \%) / 196(33.4 \%) / 242(41.3 \%)$ \\
\hline $\begin{array}{l}\text { Surgical procedure } \\
\text { Distal gastrectomy/Total } \\
\text { gastrectomy }\end{array}$ & 409 (69.8\%)/177 (30.2\%) \\
\hline $\begin{array}{l}\text { Reconstruction methods B-I/B-II/ } \\
\text { R-Y }\end{array}$ & $\begin{array}{c}279(47.6 \%) / 116(19.8 \%) / 191 \\
(32.6 \%)\end{array}$ \\
\hline $\begin{array}{l}\text { Retrieved lymph nodes (median, } \\
\text { range) }\end{array}$ & $21(3-70)$ \\
\hline $\begin{array}{l}\text { Operation time, minutes (median, } \\
\text { range) }\end{array}$ & $210.0(70.0-895.0)$ \\
\hline $\begin{array}{l}\text { Estimated blood loss, } \mathrm{mL} \text { (median, } \\
\text { range) }\end{array}$ & $100.0(5.0-7000.0)$ \\
\hline $\begin{array}{l}\text { Postoperative hospital stay, day } \\
\text { (median, range) }\end{array}$ & II (3-159) \\
\hline Pathological stage I/II/III//IV & $\begin{array}{c}137(23.4 \%) / 97(16.6 \%) / 345 \\
(58.9 \%) / 7(1.1 \%)\end{array}$ \\
\hline
\end{tabular}

Note: Variables are expressed as the mean \pm SD, median or $n(\%)$.

Abbreviations: BMI, body mass index; B-I, Billroth I reconstruction; B-II, Billroth II reconstruction; R-Y, Roux-en-Y reconstruction.

\section{Outcomes Associated with Different Seasons}

According to the season of gastrectomy, we divided the seasons into four groups: spring, summer, autumn and winter. There was no difference in terms of operation time, estimated blood loss, number of retrieved lymph nodes, complications or postoperative hospital stay ( $>0.05$ ) (Table 3 ).

\section{Outcomes of the Short and Long Preoperative Waiting Time Group}

The preoperative waiting time was divided into a shortwaiting group and a long-waiting group according to the 
Table 2 Outcomes of Midday and Non-Midday Groups

\begin{tabular}{|l|l|l|l|}
\hline Variable & Midday Group (132) & Non-Midday Group (454) & P value \\
\hline Retrieved lymph nodes (median, range) & $21(7-47)$ & $20(3-70)$ & 0.132 \\
Operation time, minutes (median, range) & $202.5(70.0-478.0)$ & $215.0(90.0-895.0)$ & $0.017^{*}$ \\
Estimated blood loss, mL (median, range) & $100.0(20.0-1000.0)$ & $100.0(5.0-7000.0)$ & 0.826 \\
Postoperative hospital stay, day (median, range) & $11(5-66)$ & $11(3-159)$ & 0.424 \\
Complications & 47 & 120 & $0.048^{*}$ \\
\hline
\end{tabular}

Note: Variables are expressed as the median, $*$ P-value $<0.05$.

Table 3 Outcomes of Different Season

\begin{tabular}{|l|l|l|l|l|l|}
\hline Variable & Spring ( I 58) & Summer (1 50) & Autumn (157) & Winter (I 2I) & P value \\
\hline Retrieved lymph nodes (median, range) & $20(5-54)$ & $21(6-49)$ & $21(3-51)$ & $19(3-70)$ \\
Operation time, minutes (median, range) & $205.0(90.0-422.0)$ & $217.5(95.0-599.0)$ & $210.0(70.0-895.0)$ & $225.0(95.0-385.0)$ & 0.765 \\
Estimated blood loss, mL (median, range) & $100(5-2000)$ & $100(20-7000)$ & $100(10-4000)$ & $100(10-2500)$ & 0.605 \\
Postoperative hospital stay, day (median, range) & $10(3-114)$ & $11(4-66)$ & $11(5-62)$ & $11(5-159)$ & 0.334 \\
Complications & 41 & 47 & 48 & 31 & 0.406 \\
\hline
\end{tabular}

Note: Variables are expressed as the median.

median. There was no significant difference in operation time, estimated blood loss, number of retrieved lymph nodes or complications $(\mathrm{p}>0.05)$. A significant difference was found in the postoperative stay, and the long-waiting group had a shorter postoperative stay than the shortwaiting group $(\mathrm{p}=0.026)$ (Table 4$)$.

\section{Overall Survival}

The median follow-up time was 28.5 (1-98) months. There was no significant difference between the short-waiting group and long-waiting group in terms of all-stage overall survival $(\mathrm{p}=0.680)$, clinical stage I overall survival $(\mathrm{p}=0.542)$, clinical stage II overall survival $(\mathrm{p}=0.269)$ or clinical stage III overall survival $(\mathrm{p}=0.815)$. Multivariate analyses for the identification of independent prognostic factors for overall survival in all clinical stage gastric cancer were performed. Age $(\mathrm{p}=0.040, \quad \mathrm{HR}=1.017, \quad 95 \% \quad \mathrm{CI}=1.001-1.033), \quad$ BMI $(\mathrm{p}<0.001, \mathrm{HR}=0.879,95 \% \mathrm{CI}=0.844-0.953)$ and clinical stage ( $\mathrm{p}<0.001, \mathrm{HR}=2.053,95 \% \mathrm{CI}=1.619-2.603)$ were independent prognostic factors for predicting overall survival; however, season of gastrectomy, surgical starting time and preoperative waiting time were not identified as an independent prognostic factors (Figure 2) (Table 5).

\section{Discussion}

A total of 586 patients were included in this study. Baseline information was collected, and short-term and long-term outcomes were compared between different time groups. The midday group had a shorter operation time but more complications, and no significant difference was found among the different season groups and preoperative waiting time groups. Furthermore, season of gastrectomy, surgical starting time and preoperative waiting time were not identified as independent prognostic factors.

The starting time of the surgery might affect the concentration of the anesthesiologist and surgeons. ${ }^{8}$ Previous studies have compared morning and afternoon surgical starting times, but it remains controversial whether morning surgical starting times have advantages over afternoon surgical starting times. ${ }^{10-12}$ Similarly, surgery during the

Table 4 Outcomes of Short and Long Preoperative Waiting Time Groups

\begin{tabular}{|l|l|l|l|}
\hline Variable & Short-Waiting Group (323) & Long-Waiting Group (263) & P value \\
\hline Retrieved lymph nodes (median, range) & $20(5-49)$ & $21(3-70)$ & 0.273 \\
Operation time, minutes (median, range) & $210.0(70.0-895.0)$ & $215.0(90.0-422.0)$ & 0.594 \\
Estimated blood loss, mL (median, range) & $100.0(10.0-4000.0)$ & $100.0(5.0-7000.0)$ & 0.114 \\
Postoperative hospital stay, day (median, range) & $11(3-114)$ & $10(4-159)$ & $0.026^{*}$ \\
Complications & 102 & 65 & 0.080 \\
\hline
\end{tabular}

Note: Variables are expressed as the median, ${ }^{*} \mathrm{P}$-value $<0.05$. 

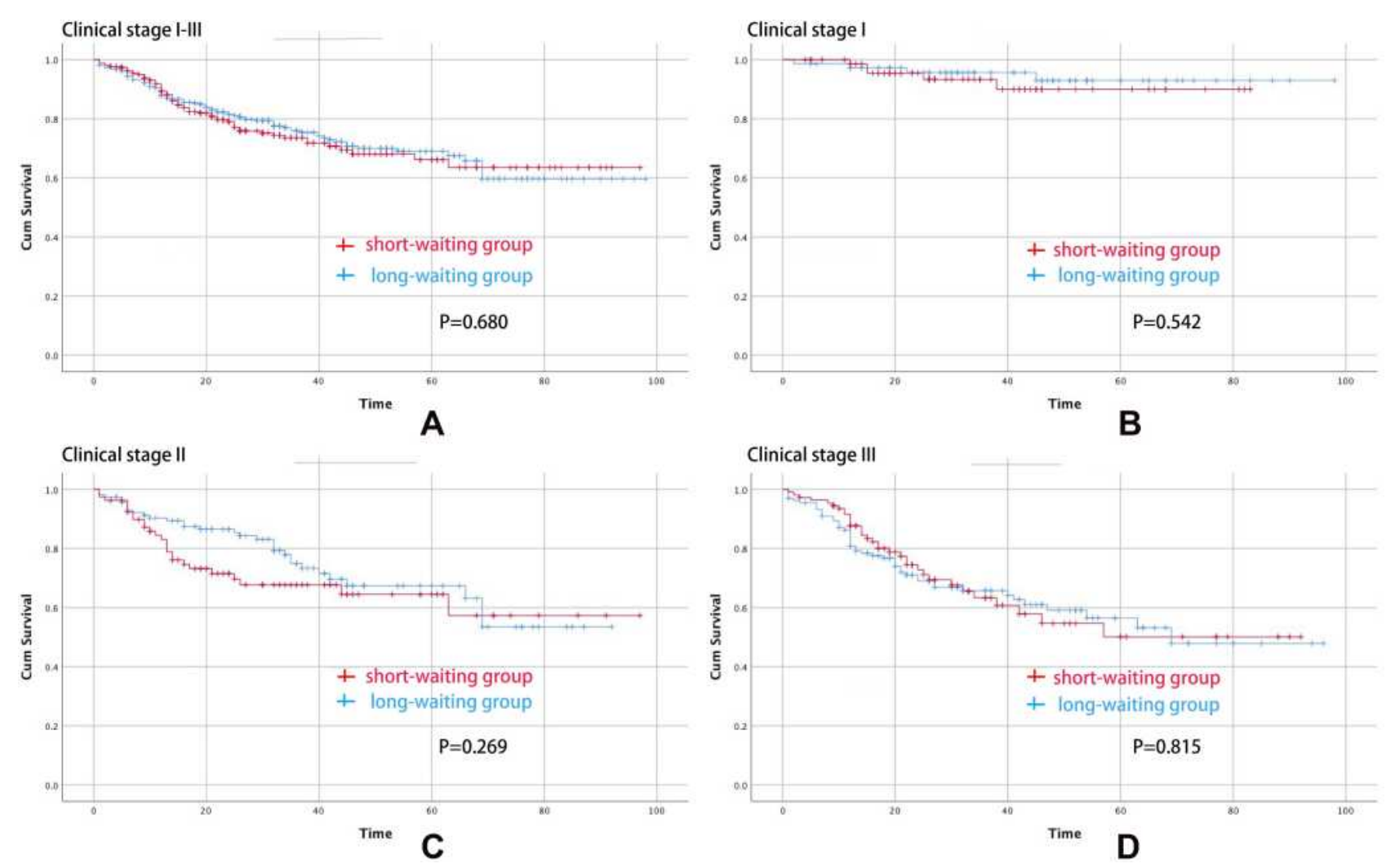

Figure 2 Overall survival curves for patients undergoing gastrectomy. (A) Overall survival curves for the waiting groups among all patients. (B) Overall survival curves for the waiting groups among clinical stage I patients. (C) Overall survival curves for the waiting groups among clinical stage II patients. (D) Overall survival curves for the waiting groups among clinical stage III patients.

Note: The red line is the short-waiting group, and the blue line is the long-waiting group.

daytime had fewer complications than at nighttime..$^{20,21}$ Workload and fatigue may be major contributors to these outcomes. China is a populous country and has the largest number of gastric cancer patients worldwide. The workload of surgeons is heavy, especially in large hospitals and can result in fatigue in surgeons. ${ }^{7,9}$ In this study, we

Table 5 Multivariate Analyses for the Identification of Independent Prognostic Factors for Overall Survival in All Clinical Stage Gastric Cancer

\begin{tabular}{|l|c|c|c|}
\hline \multirow{2}{*}{ Variables } & \multicolumn{3}{|c|}{ Multivariate Analyses } \\
\cline { 2 - 4 } & HR & $95 \% \mathrm{Cl}$ & P \\
\hline Sex (male/female) & 1.003 & $0.690-1.459$ & 0.987 \\
Age (year) & 1.017 & $1.001-1.033$ & $0.040^{*}$ \\
BMI (kg/m $\left.{ }^{2}\right)$ & 0.879 & $0.844-0.953$ & $<0.00 I^{* *}$ \\
Surgical starting time & 1.355 & $0.888-2.069$ & 0.159 \\
Season of gastrectomy & 0.969 & $0.835-1.126$ & 0.684 \\
Comorbidity & 1.049 & $0.741-1.484$ & 0.788 \\
Preoperative waiting time (day) & 1.004 & $0.990-1.019$ & 0.570 \\
Clinical stage (I/II/III) & 2.053 & $1.619-2.603$ & $<0.001 * *$ \\
\hline
\end{tabular}

Notes: *P-value $<0.05$, **P-value $<0.01$.

Abbreviations: $\mathrm{BMI}$, body mass index; $\mathrm{HR}$, hazard ratio; $\mathrm{Cl}$, confidence interval. compared the midday group and the non-midday group, and we found that the midday group had shorter operation time but more complications. In addition to workload and fatigue, the post-lunch sleepiness might account for the outcomes. Napping is common in southern China, and post-lunch sleepiness occurs whether lunch is consumed or not. ${ }^{22,23}$ There may be reasons why the midday surgical starting group might have more complications, and the careless surgical procedures might cause less surgical time.

Patients experienced a period of waiting time from diagnosis to gastrectomy. Limited hospital capacity, family members' consideration of whether to undergo surgery and preoperative comorbidity of patients can prolong the preoperative waiting time. However, the patient's psychological condition is anxious when waiting for gastrectomy. Patients worried about the tumor progression in the case of a long preoperative waiting time, especially during the coronavirus disease 2019 (COVID-19) pandemic, when the preoperative waiting time was prolonged. ${ }^{24}$ In this study, we found that the long-waiting group had a shorter postoperative hospital stay than the short-waiting group, 
however, a significant difference was not found in terms of complications and long-term survival. The cause of the shorter postoperative hospital stays of the long-waiting group remained unclear, and adequate preoperative preparation might shorten the postoperative hospital stay. Previous studies reported than a half-year wait time for surgery was not independently associated with the survival of patients with clinical stage I gastric cancer, ${ }^{13}$ and a preoperative wait time up to 90 days did not affect survival in patients with clinical stage II/III gastric cancer. $^{14}$ The results in this study were consistent with previous studies. However, delayed gastrectomy is not recommended because of the preoperative waiting timerelated psychological distress and displeasure. ${ }^{25,26}$

The season correlates with the temperature and sunlight. ${ }^{27}$ Studies on the relationship between seasons and tumors have mainly focused on the birth season and the incidence of tumors. ${ }^{16}$ Previous studies reported that persons born in spring have a higher risk of skin cancer than those born in summer, ${ }^{28}$ and for persons born in winter, the risk of lung cancer and squamous cell carcinoma was lower than those born in other seasons. ${ }^{17}$ However, there have been few reports on the impact of surgery season on patients with tumors. We hypothesized that different seasons might affect the wound healing and short-term complications. However, there was no significant difference in short-term postoperative complications between different surgical seasons in this study, which was also consistent with a previous related study. ${ }^{18}$ Therefore, our results suggested no association between the season of gastrectomy and short-term outcomes, and furthermore, season was not a risk factor for postoperative complications.

Some limitations existed in this study as well. First, this was a retrospective single-center study with 586 patients, and the number of data samples was limited. Second, the median preoperative waiting time was 10 days, which was relatively shorter than that in previous studies. Third, patients with neoadjuvant chemotherapy before gastrectomy were excluded from this study because of the prolonged preoperative waiting time. Finally, for the purpose of comparing surgical starting time in the midday group with that in the non-midday group in the daytime, we excluded gastrectomy started at night and evening; however, this might introduce some selection bias.

\section{Conclusion}

Surgical starting time at the midday could cause more complications, and a longer preoperative waiting time could shorten the postoperative hospital stay; therefore, surgeons should be careful when surgical starting time at the midday.

\section{Acknowledgments}

The authors are grateful to Dr. Zhuozhi Shen, Chongqing Center for Disease Control and Prevention, for the substantial work in the statistical methods.

\section{Author Contributions}

All authors contributed to data collection and analysis, drafting or revising the manuscript, have agreed on the journal to which the manuscript will be submitted, gave final approval of the version to be published, and agree to be accountable for all aspects of the work.

\section{Funding}

The authors received no financial support for the research, authorship, and/or publication of this article.

\section{Disclosure}

The authors declare no conflicts of interest.

\section{References}

1. Fock KM. Review article: the epidemiology and prevention of gastric cancer. Aliment Pharmacol Ther. 2014;40(3):250-260. doi:10.1111/ apt. 12814

2. Ferlay J, Soerjomataram I, Dikshit R, et al. Cancer incidence and mortality worldwide: sources, methods and major patterns in GLOBOCAN 2012. Int J Cancer. 2015;136(5):E359-E386. doi:10. 1002/ijc. 29210

3. Peng D, Cheng YX, Zhang W. Does Roux-en-Y construction really bring benefit of type 2 diabetes mellitus remission after gastrectomy in patients with gastric cancer? A systematic review and meta-analysis. Diabetes Ther. 2020;11:2863-2872. doi:10.1007/ s13300-020-00934-7

4. Tang X, Zhang M, He Q, et al. Histological differentiated/undifferentiated mixed type should not be considered as a non-curative factor of endoscopic resection for patients with early gastric cancer. Front Oncol. 2020;10:1743. doi:10.3389/fonc.2020.01743

5. Wada T, Kunisaki C, Ono HA, et al. Implications of BMI for the prognosis of gastric cancer among the Japanese population. Dig Surg. 2015;32(6):480-486. doi:10.1159/000440654

6. Gao Z, Ni J, Ding H, et al. A nomogram for prediction of stage III/IV gastric cancer outcome after surgery: a multicenter population-based study. Cancer Med. 2020;9(15):5490-5499. doi:10.1002/cam4.3215

7. Gawande AA, Zinner MJ, Studdert DM, et al. Analysis of errors reported by surgeons at three teaching hospitals. Surgery. 2003;133 (6):614-621. doi:10.1067/msy.2003.169

8. Wright MC, Phillips BB, Mark JB, et al. Time of day effects on the incidence of anesthetic adverse events. Qual Saf Health Care. 2006;15:258-263. doi:10.1136/qshc.2005.017566

9. Goitein L, Shanafelt TD, Wipf JE, et al. The effects of work-hour limitations on resident well-being, patient care, and education in an internal medicine residency program. Arch Intern Med. 2005;165 (22):2601-2606. doi:10.1001/archinte.165.22.2601 
10. Badiyan SN, Ferraro DJ, Yaddanapudi S, et al. Impact of time of day on outcomes after stereotactic radiosurgery for non-small cell lung cancer brain metastases. Cancer. 2013;119(19):3563-3569. doi:10.10 02/cncr. 28237

11. Ishiyama Y, Ishida F, Ooae S, et al. Surgical starting time in the morning versus the afternoon: propensity score matched analysis of operative outcomes following laparoscopic colectomy for colorectal cancer. Surg Endosc. 2019;33(6):1769-1776. doi:10.1007/s00464018-6449-9

12. Assali AR, Brosh D, Vaknin-Assa H, et al. The impact of circadian variation on outcomes in emergency acute anterior myocardial infarction percutaneous coronary intervention. Catheter Cardiovasc Interv. 2006;67(2):221-226. doi:10.1002/ccd.20608

13. Fujiya K, Irino T, Furukawa K, et al. Safety of prolonged wait time for gastrectomy in clinical stage I gastric cancer. Eur J Surg Oncol. 2019;45(10):1964-1968. doi:10.1016/j.ejso.2019.06.006

14. Furukawa K, Irino T, Makuuchi R, et al. Impact of preoperative wait time on survival in patients with clinical stage II/III gastric cancer. Gastric Cancer. 2019;22(4):864-872. doi:10.1007/s10120-018-00910-y

15. Brenkman HJF, Visser E, van Rossum PN, et al. Association between waiting time from diagnosis to treatment and survival in patients with curable gastric cancer: a population-based study in the Netherlands. Ann Surg Oncol. 2017;24:1761-1769. doi:10.1245/s10434-017-5820-8

16. Xiong W, Hao Y, Han L, et al. Associations between birth season and the anatomic subsites of gastric cancer in Beijing, China. Chronobiol Int. 2020;37(11):1636-1643. doi:10.1080/07420528.2020.1792481

17. Hao Y, Yan L, Ke E, et al. Birth in winter can reduce the risk of lung cancer: a retrospective study of the birth season of patients with lung cancer in Beijing area, China. Chronobiol Int. 2017;34(4):511-518. doi:10.1080/07420528.2017.1305964

18. Unal D, Oguz A, Acmaz B, et al. Lack of any association between season of diagnosis and survival of gastric cancer cases in Kayseri, Turkey. Asian Pac J Cancer Prev. 2014;15(4):1763-1766. doi:10. 7314/APJCP.2014.15.4.1763
19. Clavien PA, Barkun J, de Oliveira ML, et al. The Clavien-Dindo classification of surgical complications: five-year experience. Ann Surg. 2009;250(2):187-196. doi:10.1097/SLA.0b013e3181b13ca2

20. Becker F, Voß T, Mohr A, et al. Impact of nighttime procedures on outcomes after liver transplantation. PLoS One. 2019;14(7): e0220124. doi:10.1371/journal.pone.0220124

21. Heller JA, Kothari R, Lin HM, et al. Surgery start time does not impact outcome in elective cardiac surgery. $J$ Cardiothorac Vasc Anesth. 2017;31(1):32-36. doi:10.1053/j.jvca.2016.08.015

22. Aeschbach D, Cajochen C, Tobler I, et al. Sleep in a sitting position: effect of triazolam on sleep stages and EEG power spectra. Psychopharmacology. 1994;114(2):209-214. doi:10.1007/BF022 44838

23. Liao JQ, Xu QZ, Yuan ZY, et al. A Study on the popularity and reasons of napping in China. Chin Ergon. 2000. doi:10.1080/ 001401300404698

24. Li YX, He CZ, Liu YC, et al. The impact of COVID-19 on gastric cancer surgery: a single-center retrospective study. BMC Surg. 2020;20:222. doi:10.1186/s12893-020-00885-7

25. Gray RE, Fitch MI, Phillips C, et al. Presurgery experiences of prostate cancer patients and their spouses. Cancer Pract. 1999;7 (3):130-135. doi:10.1046/j.1523-5394.1999.07308.x

26. Robinson KM, Christensen KB, Ottesen B, et al. Diagnostic delay, quality of life and patient satisfaction among women diagnosed with endometrial or ovarian cancer: a nationwide Danish study. Qual Life Res. 2012;21(9):1519-1525. doi:10.1007/s11136-011-0077-3

27. Robsahm TE, Tretli S, Dahlback A, et al. Vitamin D3 from sunlight may improve the prognosis of breast-, colon- and prostate cancer (Norway). Cancer Causes Control. 2004;15:149-158. doi:10.1023/B: CACO.0000019494.34403.09

28. La RF, Liso A, Bianconi F, et al. Seasonal variation in the month of birth in patients with skin cancer. $B r \quad J$ Cancer. 2014;111 (9):1810-1813. doi:10.1038/bjc.2014.522
Risk Management and Healthcare Policy

\section{Publish your work in this journal}

Risk Management and Healthcare Policy is an international, peerreviewed, open access journal focusing on all aspects of public health, policy, and preventative measures to promote good health and improve morbidity and mortality in the population. The journal welcomes submitted papers covering original research, basic science, clinical \& epidemiological studies, reviews and evaluations, guidelines, expert opinion and commentary, case reports and extended reports. The manuscript management system is completely online and includes a very quick and fair peer-review system, which is all easy to use. Visit http://www.dovepress.com/testimonials.php to read real quotes from published authors. 